\title{
The University of Texas System TeleCampus: A Statewide Model for Collaboration
}

\author{
Darcy Hardy \\ The University of Texas System \\ Robert Robinson \\ The University of Texas System
}

\begin{abstract}
The University of Texas (UT) System has been meeting educational needs of students for over 150 years. In 1997, the UT System initiated the development of the UT TeleCampus, a centralized facilitation point for distance learning. The TeleCampus opened its virtual doors in May 1998, focused entirely on support services for students. By late 1998, the TeleCampus had begun developing what would become collaborative benchmark online programs for the UT System.

As a result of having developed over 12 complete online degree programs since that time, many lessons have been learned about (1) barriers to collaboration and how to overcome them; (2) faculty development and interaction; and (3) the commitment required to build successful online programs.

This article describes the UT TeleCampus initiative and how it has grown from a services-only organization to a nationally recognized model for delivering high quality distance education.
\end{abstract}

\section{Introduction}

The University of Texas System has been meeting the educational needs of students for over 100 years. The current 15 component campuses (nine academic/six health and medical) and 150,000+ students, geographically dispersed throughout the state, provide opportunities to expand horizons in a world that is now faced with and embracing an information technology revolution.

The mission of the University of Texas System is "to provide high-quality educational opportunities for the enhancement of the human resources of Texas, the nation, and the world through intellectual and personal growth" (UT System 2001 Annual Report, p. 2). The impending change in how we educate and learn in this new era, and the UT System mission of providing educational opportunities led to the creation and development of the UT TeleCampus, the centralized support unit for system-wide distance education and online learning. 
The University of Texas System TeleCampus: A Statewide Model for Collaboration

\section{The University of Texas System}

In order to best describe the UT TeleCampus and its successful collaborative programs, a short description of the University of Texas System is in order. The University of Texas was first authorized by the State Constitution in 1876. The Main Campus, now UT Austin, was founded in 1883 as a small campus of 40 acres near the state capitol. Since that time, UT Austin has become a major comprehensive research university with a broad mission of undergraduate and graduate education, research, and service to society (UT System 2001 Annual Report).

From 1891 to 1949, fourteen other campuses became part of the UT System. By Fall 2000, the System comprised:

- 153,448 students

- 79,430 employees (includes faculty)

- 14,538 faculty (all ranks)

- 29,552 degrees awarded in the 1999-2000 academic year

- \$US 5.8 billion annual operating budget

The UT System component campuses have each made efforts to increase the level of diversity among the student population. As a reflection of those efforts, no single ethnic or racial group constitutes a majority of the overall student population. Since 1998, the number of Anglo students enrolled at UT System institutions has been less than half of the entire student population. The proportion of Hispanic students has continued to grow significantly, and the proportion of African-American students has remained fairly constant. Female students constitute the majority of UT students.

The UT System is governed by a nine-member Board of Regents: Three members are appointed every two years by the Governor of Texas, and their appointments are subject to confirmation by the Texas Senate. The Board of Regents plays a critical role in many System-wide projects and initiatives, including investment decisions, campus master plans, and new leadership at component institutions. The Board made the final decision to move forward with the UT TeleCampus in August 1997. Members of the Board view distance education and the TeleCampus as vital to the mission of the UT System. Programs offered by the TeleCampus "are creating educational access and opportunities for learning and workforce development that previously were difficult or unattainable through traditional classroom-based education" (UT System 2001 Annual Report, p. 11).

International Review of Research in Open and Distance Learning 
The University of Texas System TeleCampus: A Statewide Model for Collaboration

\section{The UT TeleCampus}

The development of the UT TeleCampus was a radical departure from how the UT System traditionally met new challenges. In 1996, the System contracted with then-Andersen Consulting to review information technology initiatives at the System level and on the component campuses, and to provide a roadmap for future System-wide initiatives. As a result of the final report provided by Andersen, a Master Plan Organization (MPO) was created in early 1997 to "develop a technical and applications infrastructure to support distance education for UT System components and link to national and international initiatives." Its proposed purpose was to "use distance education to develop and share skills and apply them to enhance existing learning delivery mechanisms" (UT TeleCampus Master Plan 1997, p.2). The MPO began its work in January 1997 with a series of surveys, meetings, and campus visits. A baseline survey instrument was designed and distributed to each campus that gave the MPO information about each component's ability to offer courses at a distance. However, it was clear that the level of technology and support services for distance learning varied greatly by component.

As the MPO gathered information from the component campuses, it also looked closely at other distance education models. Penn State University had just launched its World Campus project, the Education Network of Maine was viewed as a leader in statewide programs, and the Western Governors University was in the news. The MPO also looked closely at current trends in distance education.

\section{Trends in 1997}

Student and faculty criticism of higher education's method for delivering learning had dictated a redesign of the long established manner in which this transfer of information takes place. While still effective in various situations, the instructor-centered lecture delivery of knowledge was now being seen as unacceptable as the only means of delivering educational programs; instead, the new paradigm of learner-centered electronically delivered programs was being accepted by many in higher education.

In 1997, studies had substantiated that the body of knowledge doubles every seven years and that 10,000 scientific articles were published daily. New communication and search and organization skills were required in order to sort through this voluminous amount of knowledge. In their CAUSE Paper \#14, Oblinger and Maruyama (1998) stated that these skills, to some extent, would be required by at least 95 percent of the workforce in the year 2000 . However, it was estimated that 38 percent of American households would have at least one person working in a home-based office. It was further predicted that in order to

International Review of Research in Open and Distance Learning 
The University of Texas System TeleCampus: A Statewide Model for

remain employed in the year 2000, workers would be required to absorb a certain number of continuing education courses delivered via home desktop methods.

\section{UT TeleCampus Infrastructure}

The Master Plan for the UT TeleCampus was presented to and approved by the UT System Board of Regents in August 1997. The UT TeleCampus was designed to serve the 15 component campuses by providing centralized, highquality support services for students engaged in distance learning, regardless of delivery method. At the time, the majority of all distance learning within the System was delivered via two-way interactive videoconference. The UT System utilized a dedicated T-1 network to deliver approximately 125 courses each semester, most in a point-to-point manner. Very few courses (less than 10) were available online; however, the UT TeleCampus would be designed for access via the Internet.

Two critical decisions were made during the early development of the TeleCampus. First, rather than being designed as a sixteenth component or virtual degree-granting university, the TeleCampus was designated to serve as a central support system for the distance educational initiatives of the 15 component campuses and research facilities that comprise the UT System. Second, the TeleCampus would be designed for service first and not offer courses in its first year of operation. Utilizing a unique model not followed by other virtual campuses, the UT TeleCampus spent its entire first year building student services, digital libraries, conferencing and chat capabilities, and compiling hundreds of links to learning resources that could be utilized by the general public.

The UT TeleCampus opened its virtual doors in May 1998 utilizing a "building" analogy. The TeleCampus was organized around various online buildings where distance learners (and the public) could locate specific services relevant to a variety of topics. Due to the fact that most distance courses were delivered by ITV, it was anticipated that faculty might not be willing to take courses completely online through the TeleCampus for at least a year. However, by July 1998, via discussions led by then UT System Chancellor William Cunningham, planning began for the first online degree program: The MBA Online.

\section{Collaboration at the Forefront}

Within a matter of months, the primary roles of the TeleCampus began to evolve within the UT System. Support to distance learners and faculty was made a reality through a combination of system components to share resources and create a network to support the individual components as they worked to

International Review of Research in Open and Distance Learning 
The University of Texas System TeleCampus: A Statewide Model for Collaboration

provide online programs.

A proposal developed by eight of the nine academic institutions proposed the development of a collaborative online 48-credit hour MBA program. The program would be in General Management for which each of the eight participating schools of business would develop and offer two courses. Because funding would be provided by the System (through the TeleCampus), the incentive was high to develop the program. The decision to work collaboratively ensured all campuses would receive development funding as well as tuition and fees for the courses they offered.

Since putting its first MBA courses online in 1999, the TeleCampus has expanded to offer seven fully-online Master's degrees, a Bachelor's completion program, and general undergraduate curriculum, in addition to educational certificate programs and many other stand alone courses in both academic and medical disciplines. The success of these courses and programs has affected many aspects of the UT System. (More information about the UT TeleCampus, its programs and degrees, may be found in the appendix.)

\section{The Impact of the TeleCampus on the UT System Component Institutions}

The TeleCampus functions as an external influence on individual System components. In contrast to on-campus distance education endeavors which exert change-pressure from the inside and bottom-up, the TeleCampus is able to approach each institution as a whole and externally. This allows the TeleCampus to interact with many levels of the institutions simultaneously (President, Provost, Registrars, Deans, Chairs, Faculty, etc.).

When initially created, it was hoped that the TeleCampus would initiate positive change at the component level. Specifically, it was hoped that the TeleCampus would help increase enrollments and completion rates; provide increased educational opportunities for Texas citizens; ensure high quality distance education (raise the benchmark); and provide superior digital library services. To a great extent, these goals have been met. Enrollments at the component campuses have increased and some of this is directly attributable to TeleCampus courses. The TeleCampus is making strides toward increasing general access to the educational resources of the UT System for all Texans. Seventy percent of TeleCampus students are Texas residents.

Within the State of Texas, key policy makers are focused on the issue of completion rates. There is now a strong push to motivate high school graduates to enter college as well to encourage college students to graduate. The percentage of Texans age 25 or older holding a Bachelor's degree or higher, stands at 23.9

International Review of Research in Open and Distance Learning 
The University of Texas System TeleCampus: A Statewide Model for Collaboration

percent. The national average for that same demographic segment is 26 percent (US Census Bureau, 2000). As might be expected, this is a cause for concern. The US Census Bureau notes that annual average earnings in 1999 for those ages 18 and over who had completed high school was $\$ 24,572$ and for those with a Bachelor's degree it was $\$ 45,678$.

Distance Education can clearly play a role in increasing college completion rates through the elimination of time and geography barriers. Courses and degree programs offered by the TeleCampus allow working individuals and those with family commitments to continue their studies. While the TeleCampus has focused on graduate programs to date, it is establishing its first undergraduate completion program in the spring of 2002. This program will allow students who have completed lower division requirements (or who have an Associate's degree) to earn their Bachelor's degree entirely online.

Quality has been a driving factor behind the TeleCampus from its inception. Faculty members remain the center of attention, as they are ultimately responsible for the quality of the offerings. Assisting the faculty to become more skilled in the areas of online teaching and learning is a key to assuring quality. Each year the TeleCampus offers several faculty instructional design trainings. These sessions educate faculty in core instructional design issues, as well as on the intricacies of copyright and intellectual property issues. Each faculty member is asked to complete a self-study based on the Western Interstate Commission on Higher Education, "Principles of Good Practice for Electronically Delivered Courses and Programs" (WICHE, 1999) elements of design and method for student-faculty interaction. In addition, the Telecampus conducts technical training for campus-based support staff on the use of courseware and technology tools. Through these efforts, there has been a general rise in the level of quality seen in Web-based distance education courses taught across the UT System.

Clearly the TeleCampus has had an impact on the component institutions of the UT System. While some aspects of that impact were expected, it is interesting to examine the unintended consequences of the TeleCampus. One of the direct results of TeleCampus can be seen in the creation of distance education centers at several campuses. These are formal departments that focus on creation and support of Web-delivered courses within the TeleCampus model. These centers work directly with their campus faculty, easing the burden on the TeleCampus staff. The evolution of these distance education centers has been accelerated as a result of the TeleCampus course development grants.

While the TeleCampus can be thought of a collaborative endeavor within the loose federation of autonomous universities that comprises the UT System, collaboration among the 15 institutions has not been common. The TeleCampus now seems to function as a "collaboration engine" within the System. As the programs become more visible and continue to demonstrate success, the TeleCampus model of collaboration is beginning to appear in other arenas within the UT System. Several non-distance-based collaborative degree programs have 
been announced and several technology-based joint projects are underway across multiple campuses. These collaborative efforts are not just inter-institutional. A new focus on cross-departmental and cross-functional projects is becoming more visible. Administrative units (campus registrars, financial aid officers, etc.) are beginning to work actively with academic units in support of collaborative programs.

The growth and success of the TeleCampus to date also increases the awareness of the possibilities brought on by distance education. Several institutions have been approached by outside entities (i.e., other universities, corporations, the Department of Defense), to enroll cohorts, develop courses, or repackage existing courses. Overall, there is a growing realization that distance education provides an opportunity to serve markets not previously served.

\section{Lessons Learned}

While there is still much to learn about this brave new world of Web-based distance education, we have learned some valuable lessons. These can be categorized according to several constituent groups:

\section{Students}

- Web-based distance education is not appropriate for every student. Successful distant students are goal-oriented and self-directed. As a general trend, these are traits found more often in older students. The very flexibility that draws students to web-based courses also requires more selfdiscipline from the student in order to be successful.

- Many students are not as technologically literate as initially assumed. It is not the technology that attracts students; it is the time- and placeindependence. The technology is often seen as a hurdle rather than as an enabler. The technological capabilities of the students vary greatly, generally program by program. For example, engineering students are highly technically skilled, while students in education programs tend to be technology-shy.

- Students have "dot-com" expectations. Information and services must be delivered quickly and accurately. Students do not tolerate downtime, and they want services delivered electronically and in real time.

- Given the opportunity to communicate, students will. It is imperative to make as many communications channels as possible available. The frequency and quality of feedback received from students has been impressive.

International Review of Research in Open and Distance Learning 
The University of Texas System TeleCampus: A Statewide Model for

\section{Faculty}

- Use of tenured faculty greatly increases program credibility. By engaging tenured faculty members to "repackage" their knowledge for delivery over the web, great value is added to each course. Adjunct faculty members certainly have their place in this realm, but the use of predominately tenured faculty seems to be a strong factor in persuading students to begin our programs.

- Training is critical. (Corollaries: Faculty may not be as technologically literate as they claim. Most are not familiar with instructional design issues. Separate pedagogical issues from technological ones.) While many faculty members have been using technology for some time in their oncampus courses, ample training must be provided in the areas of specific technologies, instructional design, and effective online teaching methods. The key here is making this training available and useful without insulting the faculty. In addition, it is important to keep faculty focused on the content. Preferably, faculty will not be handling the actual nuts-and-bolts tasks of getting content into the courseware platform, as this only detracts from important content and design issues.

- Copyright and ownership are important motivators. In the TeleCampus model, faculty, or faculty and campus jointly, own the copyright on the content of the courses. The TeleCampus then contracts with the copyright holder for a right-to-use over a period of years. This policy has proven a great incentive toward faculty involvement with the TeleCampus.

- Faculty can be difficult to work with. We constantly search for the right balance between academic freedom and quality assurance. This conflict is heightened in an online environment. Standardizing course design/navigation elements and technology choices is necessary to ensure a consistent high quality experience for the student. However, faculty can view these decisions as constraints to academic freedom.

\section{Administrators}

- Communication is vital. Certainly this can be said for all the constituent groups. However, it is especially vital to keep all appropriate administrators up-to-date. Here we are referring to registrars, financial aid officers, provosts, deans, presidents, etc. Since this is a group that is not close to the development and delivery of courses, establishing communication might be inadvertently overlooked. However, leaving administrators out of the loop will certainly hamper one's ability to implement programs and policy. Successful collaboration is built on information flowing in all directions. 
The University of Texas System TeleCampus: A Statewide Model for

- Money talks. With the TeleCampus directly funding course development, cooperation came easily. As we move away from the direct subsidy model, we must work harder to maintain these collaborative efforts

- Find the balance between collaborator vs. owner. (Corollary: Administrators will always first defend their own institution.) Everyone involved agrees that there is great value in our collaborative programs, yet the institutions all want each program to be specific to their campus. At the same time, it is important for the TeleCampus to foster a sense of ownership among the administrators in the System.

- Document, document, document! All agreements between the TeleCampus and the components must be documented, and these documents must be kept up-to-date. Contracts, memoranda of understanding, manuals of operating procedures, etc., all become key resources as the faces and roles of the stakeholders change over time.

\section{Policy Makers (Federal, State, Accreditors, Regents, etc.)}

- Being well funded by policy makers means we are also beholden. It is important to periodically reassess organizational direction and make sure it is in line with the mission and goals of the policy makers.

- Funding does not last forever. Perpetual central funding should not be assumed. We are always investigating new methods of developing revenue in support of our programs.

- Stakeholders change. Being a state institution, our future direction can change with the next election. Priorities and policies are constantly evolving at the state and national level. The TeleCampus tends to be highly visible and thus must stay attuned to this changing political landscape.

\section{Implications for Distance Education Research and Practice}

With the success of the UT TeleCampus, there are implications for research and practice in the field. Why do some virtual universities succeed? Why do others fail? One of the key reasons for success of the TeleCampus is the collaborative nature of its programs. However, collaboration is not easily accomplished on an individual campus, much less across an entire university system. Brian Hawkins, president of Educause, stated recently that: "the ability to truly collaborate is one of the greatest challenges facing higher education today" (2001, Educause Review, p. 56). It is understandable then why many universities choose to

International Review of Research in Open and Distance Learning 
develop distance education on their own. After all, collaboration takes a significant level of commitment by all parties, and it requires more work hours to achieve success.

One other factor that causes breakdown in collaborative efforts can be called the "not invented here" syndrome. Although often discussed in private conversations, it is rarely discussed formally. In our work with the TeleCampus collaborative programs, this has proven to be a major barrier. One might expect this syndrome from the flagship, Research One institution in a university system, but our experience is that it is found on any university campus. The nature of higher education seems to force faculty into a competitive stance. Fifteen faculty members may teach History 101 at 15 different campuses, and each will insist that his or her course is the only way the course should be taught.

For collaborative programs to work, and for agreements to be made on curriculum decisions, all voices must be heard. For each collaborative program creating a "community of scholars" that did not threaten any one person's views about teaching strategies was an important step in the process. Each collaborative TeleCampus program includes an Academic Affairs Oversight Committee. These groups consist of faculty from all participating institutions (in the appropriate discipline areas), some who may be teaching in the program, and some who may not. Through these committees, faculty members are controlling the program in a shared fashion, and no one campus has the final say about curriculum. Evidence has indicated that a "faculty's strong sense of shared values and directions reduces the need for codified structures and procedures" (Chopp, Frost, \& Jean, 2001, p. 45). Once the programs are launched, the Academic Affairs Committees meet twice a year to review programs and discuss new curriculum ideas. Additional research is recommended in the area of building faculty trust and support for collaborative programs across institutions and university systems.

The much-discussed issues of copyright and intellectual property continue to plague distance education. Throughout the development of courses and programs for the UT TeleCampus, it became apparent that a large number of faculty members were unaware of their rights regarding their own intellectual property. Many assume that the university has no rights to their intellectual property in an online course. Others assume the opposite, believing that they have no rights themselves and that the university has the sole copyright to their work. Neither assumption is completely correct. Georgia Harper, copyright attorney for the UT System, and nationally recognized for interpretations of copyright law in a digital era, has developed a Website to help faculty understand the rules of ownership (http://www3.utsystem.edu/ogc/intellectualproperty/whowns.htm. ). All faculty involved in TeleCampus programs are encouraged to read through Ms. Harper's documentation. After reading, most agree with James Hilton, who states: "If I have discovered a single truth about copyright law, it is that my intuitions are almost always wrong" (Hilton, 2001, p. 48). 
The University of Texas System TeleCampus: A Statewide Model for Collaboration

While the TeleCampus itself has become less concerned with "who owns what," and more concerned with "use," our faculty and campuses are beginning to focus more on use as well. In the early days of online learning, many faculty members believed they could develop a course and sell it for a large profit. A few star faculty have indeed been able to sell content, but not for the amounts of money originally assumed. The fact is that most faculty members will never sell their content to anyone outside the university. As far as ownership concerns, an author automatically has the rights to his or her work. Determining who else has rights to that work is a decision to be made between the institution and the faculty member. However, how the work is used can be the decisive factor on whether an online course or program can continue after the faculty member leaves the institution. In our opinion, this is where more work should be done. Contracts, agreements, and decisions must all be made today based on use. Unfortunately, many institutions are still dealing with ownership issues of the present, and not focusing enough attention on the future of their programs.

The TeleCampus is currently addressing two areas of online learning: tracking of graduates and outcomes assessment to determine success rates. Since the TeleCampus launched its first courses in the fall of 1999, we are just seeing our first program graduates. It is our intent to track these graduates to determine first how their online degree is accepted by hiring entities, and second, if the fact that they received the program online enhances their current employment opportunities. Most of the graduate students enrolled in TeleCampus programs are working and, in some cases, the employer is funding the educational experience.

Tracking graduates may prove to be a relatively easy task as compared to determining success rates. In Fall 2000, the TeleCampus saw an 85 percent completion rate among its $1,000+$ enrollments. Over the past two years, the TeleCampus has won eight regional and national awards. But those two facts do not necessarily mean that the TeleCampus programs have been successful in meeting the overall outcome expectations of each program. In April 2001, the TeleCampus was visited by a team from its regional accreditation agency, the Southern Association for Colleges and Schools (SACS). Even though the TeleCampus is ineligible for accreditation (it does not admit students or award credit or degrees), SACS officials felt it necessary to review the collaborative programs facilitated by the TeleCampus.

The final report from the visitation team was positive overall. Members of the committee were impressed with the collaborative nature of the programs, the support services offered to students by the TeleCampus, and the oversight and control provided by the participating component institutions. However, a primary question asked by the team was related to program outcomes and how their success was being determined. As a result of the report, Academic Affairs Committees for each program now focus on the development of specific outcomes for each collaborative effort. Most outcomes resemble campus-based

International Review of Research in Open and Distance Learning 
outcomes, although there are some variations. Once all outcomes are identified, the TeleCampus will facilitate an assessment to determine levels of success, a process expected to take as long as two years.

\section{Conclusion}

This article is but one example of inter-institutional collaboration in higher education. The experience of the TeleCampus has revealed that while distance education in an historical sense has been a grass roots effort, the high costs and risks associated with distance education today require a top-down approach. The University of Texas System Board of Regents and its component institutions realized that by providing seed money and sharing resources, it was possible to build a truly collaborative, centralized, distance education program.

The lessons learned by the TeleCampus over the past four years, while often difficult to accept, have contributed significantly to its success. In response to the many barriers faced, new policies, procedures, and operating methods were devised. Each small success presented new challenges, but as each challenge was met, the overall impact of the TeleCampus increased.

Opportunities for research in distance education continue to present themselves. However, the advent of collaborative models brings a new level of need for empirical research. Some of the questions yet to be answered completely include:

How best to offer incentives for collaboration? What are the appropriate policies regarding copyright and royalty issues? How to judge overall program effectiveness? 
The University of Texas System TeleCampus: A Statewide Model for Collaboration

\section{References}

Chopp, R.S., Frost, S.H., \& Jean, P.M. (2001, November/December). What's old is new again. Change, The Magazine of Higher Learning, 33(6), 43-47.

Hawkins, B. L. (2001, September/October). Information access in the digital era. Educause Review, 36(5), 54-57.

Hilton, J. (2001, November/December). Copyright assumptions and challenges. Educause Review, 36(6), 48-51.

Oblinger \& Maruyama (1998). CAUSE Paper \#14.

US Department of Commerce, Economics and Statistics Administration (2000, March). Texas Table Data from Educational attainment of people 18 years and over, by age, sex, race, and Hispanic origin, for the 25 largest states. US Census Bureau: Educational attainment in the United States.

The University of Texas System 2001 Annual Report. Published by The University of Texas System, Austin.

UT TeleCampus Master Plan (1997).

Principles of Good Practice for Electronically Offered Academic Degree and Certificate Programs (1999, September) Western Interstate Commission for Higher Education http://www.wiche.edu/telecom/projects/balancing/principles.htm.

\section{APPENDIX}

UT TeleCampus at a glance: www.telecampus.utsystem.edu .

\section{Mission and Operating Principles}

The UT TeleCampus is a service-driven, central support system for online education initiatives among the 15 UT System universities and research facilities. Key to the UT TeleCampus operations are the following guiding principles:

- All UT TeleCampus activities must be consistent with the mission of The University of Texas System in its effort to provide access and high-quality educational opportunities for Texans.

- The UT TeleCampus would not exist without the support of the UT System faculty.

- The TeleCampus must promote and support UT faculty throughout online course development and delivery.

International Review of Research in Open and Distance Learning 
The University of Texas System TeleCampus: A Statewide Model for

\section{Historical Overview}

The UT TeleCampus was launched in May 1998, with a Web site designated to serve as a central support system for the online educational initiatives of the 15 component campuses and research facilities (as opposed to being designed as a sixteenth component or virtual degree-granting university). In its first year, the TeleCampus did not offer courses. Utilizing a unique model, the TeleCampus spent its entire first year building student services, digital libraries, conferencing and chat capabilities, and compiling hundreds of links to learning resources that could be utilized by the general public.

In placing programs online, the TeleCampus sought to assist in the creation of collaborative degrees, utilizing the best resources in faculty expertise from all campuses. This model was defined in the first degree programs offered via the TeleCampus: The MBA Online and the MEd in Educational Technology. Both were launched in the fall of 1999. The MBA Online degree is conferred from any one of seven participating campuses, with eight campuses contributing courses to the degree plan. The MEd degree is conferred from UT Brownsville, with UT El Paso, UT Austin, UT Permian Basin, and UT Medical Branch also providing courses toward the degree plan. Today the UT TeleCampus houses six master's degrees, undergraduate curriculum and certificate programs. Though its focus is online degrees, the TeleCampus also supports several other courses (not part of a fully-online degree) in medicine and allied health in addition to a growing menu of academic choices. As a service to our campuses, the TeleCampus site also posts a searchable database of all distance education courses System-wide, regardless of delivery format.

To support the development of these programs, the UT TeleCampus provides funding for course development, in addition to providing specialized training to UT faculty teaching online via the TeleCampus. Extensive support services are provided by TeleCampus staff including instructional design, student services, technological support, policy, marketing research, and external communications.

The UT TeleCampus website sees an increasing volume of traffic with each semester and currently logs more than half a million hits and 17,000 unique users a month. When the TeleCampus opened its virtual classroom doors in fall of 1999, there were 189 enrollments spread between two programs. In fall 2000, enrollments exceeded 1,000 across half a dozen programs and in fall 2001 enrollments exceeded 2,000.

\section{UT TeleCampus Degrees and Programs}

All degree programs offered via the UT TeleCampus can be completed entirely at a distance, removing geographic-based barriers to learning. Programs run on a semester basis, and courses are paced during the semester. Listed below 
The University of Texas System TeleCampus: A Statewide Model for Collaboration

are current TeleCampus programs and the component campuses participating in each one. As mentioned previously some campuses contribute courses, others contribute courses and confer the degree listed.

- MBA Online (UT Arlington, UT Brownsville, UT Dallas, UT El Paso, UT Pan American, UT Permian Basin, UT San Antonio, UT Tyler)

- Master's in Educational Technology (UT Brownsville, UT Austin, UT El Paso, UT Medical Branch)

- Master's in Curriculum and Instruction - Reading Specialization (UT Arlington)

- Master's in Kinesiology (UT Permian Basin, UT San Antonio, UT Arlington, UT Pan American, UT Tyler, UT El Paso)

- Master's in Electrical Engineering (UT Arlington, UT Dallas)

- Master's in Computer Science (UT Arlington, UT Dallas)

- Master's in Computer Science and Engineering (UT Arlington,)

- English as a Second Language Endorsement (UT Arlington)

- First Year Online (UT Arlington, UT Austin, UT Brownsville, UT Pan American, UT Permian Basin)

- Dual Credit Program (UT Arlington, UT Austin, UT Brownsville, UT Pan American, UT Permian Basin)

- Texas Professional Development Online-Algebra (UT TeleCampus)

- Chess in Education Online (UT Dallas)

- Bachelor's Completion Program in Criminology and Criminal Justice Online (UT Arlington, UT Brownsville, UT Permian Basin)

Oversight committees or Academic Advisory Committees exist for each online degree program. These committees ensure the quality and integrity of the courses. They are comprised of deans and faculty represented from the schools participating in any degree program.

\section{Student Demographics}

Each semester, the TeleCampus Marketing and Communications group surveys students enrolled in TeleCampus courses. Though demographics shift slightly from semester to semester, they remain fairly constant. Most students are from Texas. In Spring 2001 for example almost 75 percent were from Texas. The

International Review of Research in Open and Distance Learning 
The University of Texas System TeleCampus: A Statewide Model for Collaboration

remaining one-fourth of the student population includes representatives from 26 states and eight countries. No students are required to divulge ethnicity; however, about 75 percent elect to self-identify. The TeleCampus classrooms are diverse. Approximately 50 percent of the students identified themselves as Caucasian, 16 percent Hispanic, 6 percent Asian, and 4 percent African American. Less than 1 percent categorized them selves as either American Indian or "other."

When asked, students consistently point to the flexibility and portability of online learning as their motivation for choosing to learn via the UT TeleCampus. Almost half reported looking at other online programs outside of the System prior to selecting the UT TeleCampus. About half were truly distance learners; while the other half were taking at least one on-campus course in addition to their online course.

\section{UT TeleCampus Awards}

In the months following the launch of its first online degree programs the UT TeleCampus began receiving regional and national attention, accolades and awards:

- Golden Web Award for excellence in web design and content

- Texas Distance Learning Association Service Award

- University Continuing Education Association (UCEA) Outstanding Distance Learning Course

- US Distance Learning Association - Excellence in Distance Teaching, Higher Education

- US Distance Learning Association - Excellence in Distance Learning Programming

- UCEA - Excellence for a Credit Program (ESL Endorsement)

- UCEA Region III - Excellence for a Non-Credit Program (Instructional Design Tutorial)

- Best Site - Snap.com

- Peterson's/UCEA Most Innovative Distance Education Program

- Three first place Best of Austin Awards from the International Association of Business Communicators in the following fields: brochure, writing, and radio spot.

International Review of Research in Open and Distance Learning 
The University of Texas System TeleCampus: A Statewide Model for Collaboration

Reference: More information about the UT TeleCampus can be found in the UT TeleCampus Report 2000, and on the website at http://www.telecampus.utsystem.edu.

Citation Format

Hardy, Darcy W. \& Robinson, Robert l. (January, 2002) The University of Texas System TeleCampus: A Statewide Model for Collaboration. International Review of Research in Open and Distance Learning: 2, 2. http://www.icaap.org/iuicode?149.2.2.4

International Review of Research in Open and Distance Learning 